\title{
Bioreactor production of rVSV-vectored vaccines in Vero cell suspension cultures
}

\author{
Sascha Kiesslich ${ }^{1}$, Gyoung Kim², Chun Fang Shen ${ }^{3}$, Chil-Yong Kang ${ }^{2}$, and Amine Kamen ${ }^{1}$ \\ ${ }^{1}$ McGill University \\ ${ }^{2}$ University of Western Ontario Schulich School of Medicine and Dentistry \\ ${ }^{3}$ National Research Council Canada
}

January 12, 2021

\begin{abstract}
The Vero cell line is the most used continuous cell line in viral vaccine manufacturing. This adherent cell culture platform requires the use of surfaces to support cell growth, typically roller bottles or microcarriers. We have recently compared the production of rVSV-ZEBOV on Vero cells between microcarrier and fixed-bed bioreactors. However, suspension cultures are considered superior with regards to process scalability. Therefore, we further explore the Vero suspension system for rVSVvectored vaccine production. Previously, this suspension cell line was only able to be cultivated in a proprietary medium. Here, we expand the adaptation and bioreactor cultivation to a serum-free commercial medium. Following small scale optimization and screening studies, we demonstrate bioreactor productions of highly relevant vaccines and vaccine candidates against Ebola virus disease, HIV and COVID-19 in the Vero suspension system. rVSV-ZEBOV, rVSV-HIV and rVSVInd-msp-SF-Gtc can replicate to high titers in the bioreactor, reaching $3.87 \times 107$ TCID50/mL, $2.12 \times 107$ TCID50/mL and $3.59 \times 109$ TCID50/mL, respectively. Further, we compare cell specific productivities, and the quality of the produced viruses by determining the ratio of total viral particles to infectious viral particles
\end{abstract}

\section{Bioreactor production of rVSV-vectored vaccines in Vero cell suspension cultures}

Sascha Kiesslich ${ }^{1}$, Gyoung Nyoun Kim² ${ }^{2}$ Chun Fang Shen ${ }^{3}$, C. Yong Kang ${ }^{2}$, Amine A. Kamen ${ }^{1, *}$

${ }^{1}$ Department of Bioengineering, McGill University, 817 Sherbrooke Street West, Montreal, Quebec H3A 0C3, Canada

${ }^{2}$ Department of Microbiology and Immunology, Schulich School of Medicine and Dentistry, The University of Western Ontario, London, Ontario N6G 2V4, Canada

${ }^{3}$ Human Health Therapeutics Research Center, National Research Council of Canada, 6100 Royalmount Ave, Montreal, Quebec H4P 2R2, Canada

*Address correspondence to: Amine A. Kamen, Department of Bioengineering, McGill University, 817 Sherbrooke Street West, Montreal, Quebec H3A 0C3, Canada. E-mail: amine.kamen@mcgill.ca

\section{Abstract}

The Vero cell line is the most used continuous cell line in viral vaccine manufacturing. This adherent cell culture platform requires the use of surfaces to support cell growth, typically roller bottles or microcarriers. We have recently compared the production of rVSV-ZEBOV on Vero cells between microcarrier and fixedbed bioreactors. However, suspension cultures are considered superior with regards to process scalability. 
Therefore, we further explore the Vero suspension system for rVSV-vectored vaccine production. Previously, this suspension cell line was only able to be cultivated in a proprietary medium. Here, we expand the adaptation and bioreactor cultivation to a serum-free commercial medium. Following small scale optimization and screening studies, we demonstrate bioreactor productions of highly relevant vaccines and vaccine candidates against Ebola virus disease, HIV and COVID-19 in the Vero suspension system. rVSV-ZEBOV, rVSV-HIV and $\mathrm{rVSV}_{\text {Ind }}-m s p-\mathrm{S}_{\mathrm{F}}-G t c$ can replicate to high titers in the bioreactor, reaching $3.87 \times 10^{7} \mathrm{TCID}_{50} / \mathrm{mL}$, $2.12 \times 10^{7} \mathrm{TCID}_{50} / \mathrm{mL}$ and $3.59 \times 10^{9} \mathrm{TCID}_{50} / \mathrm{mL}$, respectively. Further, we compare cell specific productivities, and the quality of the produced viruses by determining the ratio of total viral particles to infectious viral particles.

\section{Keywords}

Vero suspension culture

Viral vaccine bioprocess

Bioreactor production

rVSV-ZEBOV

COVID-19

\section{Abbreviations}

COVID-19 = coronavirus disease 2019

$\mathrm{HIV}=$ human immunodeficiency virus

hpi $=$ hours post-infection

MOI $=$ multiplicity of infection

TOI $=$ time of infection

rVSV $=$ recombinant vesicular stomatitis virus

\section{Introduction}

Recombinant vectored vaccines produced in cell culture are receiving increased attention in the fight against infectious diseases. More and more vaccines are available that are based on this technology and research efforts to develop new vaccines or to improve current manufacturing processes have intensified over the last years (Ura et al., 2020). One such system is based on the recombinant vesicular stomatitis virus (rVSV). In addition to its use as a vaccine vector, VSV has been used extensively in many areas of research, for example as an oncolytic virus or as a gene delivery tool (Lichty et al., 2004)(Munis et al., 2020).

VSV is a replication-competent virus with a single-stranded, negative-sense RNA genome. The native glycoprotein, VSV-G, is responsible for viral entry into the cell. When genetically engineered to express the glycoprotein of another virus, rVSV can be used as a vaccine vector by delivering foreign antigens (Munis et al., 2020). The advantage of such a vectored vaccine is the increased safety during manufacturing, since the production of live-attenuated or inactivated vaccines of highly pathogenic viruses (e.g. HIV, Ebola) would require stringent biosafety standards. The recent success story of the EMA and FDA-approved Ebola vaccine rVSV-ZEBOV showcases the potential of the rVSV platform (Henao-Restrepo et al., 2017). rVSV-ZEBOV is a replication competent virus in which VSV-G was replaced by a Zaire Ebolavirus glycoprotein (ZEBOV), 
which is the main antigen of the Ebolavirus. Several rVSV-based vaccines are in development, for example against measles, Lassa fever and Middle East respiratory syndrome (MERS) (Henao-Restrepo et al., 2017; Kiesslich and Kamen, 2020; Munis et al., 2020).

In the light of the progress achieved with rVSV-ZEBOV, three novel rVSV constructs have been described recently, which carry different glycoproteins of the Human Immunodeficiency Virus (HIV) (Mangion et al., 2020). These HIV-vaccine candidates were produced in adherent Vero cells in tissue culture plates and it was demonstrated that they induced an HIV gp140-specific antibody response when administered to mice. The rVSV-B6-A74Env(PN6)/SIVtm construct was selected for further studies in non-human primates.

In the current race for a COVID-19 vaccine, recombinant vectored vaccines produced in cell culture are amongst the most promising (Ura et al., 2020). For example, ChAdOx1 $\mathrm{nCoV}-19$, developed by the University of Oxford, is based on a chimpanzee adenovirus-vectored vaccine expressing the SARS-CoV-2 spike protein (Folegatti et al.,) and its safety, efficacy, and immunogenicity is being assessed in a phase III clinical trial (NCT04516746). Besides, several rVSV-based COVID-19 vaccine candidates expressing the SARS-CoV-2 spike protein are being evaluated in preclinical trials (University of Manitoba, Canada; University of Western Ontario, Canada; Aurobindo Pharma, India; Israel Institute for Biological Research/Weizmann Institute of Science, Israel; FBRI SRC VB VECTOR, Russia) and a phase I clinical trial (Merck Sharp \& Dohme/IAVI; NCT04569786) (World Health Organization, 2020). The COVID-19 vaccine candidate $\mathrm{rVSV}_{\text {Ind }}-m s p-\mathrm{S}_{\mathrm{F}}-$ Gtc, is a temperature-sensitive construct. It is based on a recombinant VSV $_{\text {Ind }}$ (GML) mutant, and shows avirulent in vivoreduced cytopathic effect in vitro at $37^{\circ} \mathrm{C}$, but replicates well at $31^{\circ} \mathrm{C}$ (Kim et al., 2015). This attenuation was used as a strategy to further increase the safety of rVSV for its use as a human vaccine. $\mathrm{rVSV}_{\text {Ind }}-m s p-\mathrm{S}_{\mathrm{F}}-$ Gtc is expressing the SARS-CoV-2 spike protein gene, the honeybee melittin signal peptide gene and the VSV-G protein transmembrane domain gene.

Currently, the rVSV-ZEBOV vaccine is manufactured under serum-free conditions in adherent Vero cells using the roller bottle technology (Monath et al., 2019). To reduce manufacturing costs, more scalable bioprocesses involving microcarrier bioreactors and fixed-bed bioreactors have been studied recently (Kiesslich et al., 2020). However, these adherent cell processes still have scale-up limitations, for example the cell expansion steps during the seed train operation require cell detachment from and re-attachment to surfaces, usually involving enzymatic solutions such as trypsin. Suspension cell systems are considered superior with regards to process scale-up, since the transfer of cells to successively larger bioreactor vessels is straightforward.

Adherently growing Vero cells are the most used continuous cell line in viral vaccine manufacturing. For example, vaccines against Ebola, influenza, Japanese encephalitis, polio, rabies, rotavirus and smallpox are available on the market and vaccines against other infectious diseases are under development, using this cell line. The many advantages of this cell line are its broad susceptibility to many viruses, the long-term experience in cell culture and the regulatory portfolio associated with vaccine manufacturing organization and health authorities worldwide (Kiesslich and Kamen, 2020).

Adaptation of the Vero cell line to grow in suspension culture to significantly improve this cell culture manufacturing platform has been of interest for many years (Litwin, 1992; Paillet et al., 2009). Lately, studies have reported the successful adaptation using proprietary media (Rourou et al., 2019; Shen et al., 2019). Shen et al. showed that Vero cells can grow in suspension culture in serum-free batch and perfusion bioreactors, and successfully applied their system to the production of rVSV-GFP, which uses the native glycoprotein VSV-G for viral entry into the cell.

In this work, we further explore the Vero suspension system described previously (Shen et al., 2019), and demonstrate its applicability to relevant rVSV-based vaccine candidates. Using rVSV-ZEBOV as a model for rVSV, we focus on small scale experiments to optimize the multiplicity of infection (MOI) and investigate effects of different cell densities. Next, we compare the production of rVSV-ZEBOV in this system to the production in Vero cells that were adapted to grow in suspension culture in a commercially available medium. In addition, we show the production of newly developed candidate vaccines against HIV (rVSV-HIV) and COVID-19 ( $\mathrm{rVSV}_{\text {Ind }}-m s p-\mathrm{S}_{\mathrm{F}}-$ Gtc $)$. Based on these results, we demonstrate production in batch bioreactor 
for all three rVSV variants.

\section{Materials \& Methods}

\section{Cell line and culture media}

The suspension adapted Vero cell line was provided by the National Research Council (NRC) of Canada, Montreal, Canada, and its adaptation process has been described previously (Shen et al., 2019). For routine passaging, the cells were harvested by centrifugation for 5 minutes at $500 \mathrm{~g}$ and the cell pellet was resuspended in fresh medium to a seeding cell density of $2.5-5 \times 10^{5}$ cells $/ \mathrm{mL}$ in $125 \mathrm{~mL}$ polycarbonate shake flasks (TriForest Enterprises, USA) and maintained at $37{ }^{\circ} \mathrm{C}, 135 \mathrm{rpm}$ and $5 \% \mathrm{CO}_{2}$ in an humified Multitron orbital shaker (Infors HT, Switzerland). The cells were cultivated in $20 \mathrm{~mL}$ working volume of either IHM03 medium, provided by the NRC, or in MDXK medium (Xell AG, Germany), supplemented with $4 \mathrm{mM}$ GlutaMAX (Thermo Fisher Scientific, USA).

\section{Viruses}

Origin and viral seed stock amplification of rVSV-ZEBOV and rVSV-B6-A74Env(PN6)/SIVtm (hereafter referred to as rVSV-HIV) have been described previously (Kiesslich et al., 2020) (Mangion et al., 2020).

The recombinant COVID-19 vaccine candidate $\mathrm{rVSV}_{\text {Ind }}-m s p-\mathrm{S}_{\mathrm{F}}-$ Gtc was constructed as follows: Codonoptimized full-length spike protein gene of SARS-CoV-2 (GenBank: JX869059.2) was purchased from Genscript USA Inc (Pscataway, NJ, USA), cloned into an avirulent Indiana serotype of vesicular stomatitis virus $\left[\mathrm{VSV}_{\text {Ind }}(\mathrm{GML})\right]$ as has been described previously (Kim et al., 2015). The honeybee melittin signal peptide ( $m s p$ ) was inserted at the $\mathrm{NH}_{2}$-terminus and the transmembrane domain and cytoplasmic tail (Gtc) of the $\mathrm{S}$ protein was substituted by the Gtc of $\mathrm{VSV}_{\text {Ind }} \mathrm{G}$ protein at the $\mathrm{COOH}$-terminus. In addition, the VSV intergenic sequences were added in front of the spike protein gene in order to provide the transcription termination signal, polyadenylation signal, and the transcription re-initiation signal. The modified SARS-CoV-2 spike protein gene was inserted into the $\mathrm{G}$ and $\mathrm{L}$ gene junction of the $\operatorname{VSV}_{\text {Ind }}(\mathrm{GML})$ at $P m e I$ and $M l u I$ sites. Recombinant $\mathrm{rVSV}_{\text {Ind }}-m s p-\mathrm{S}_{\mathrm{F}}-$ Gtc virus was recovered by VSV reverse genetics as has been described previously (Kim et al., 2015). The recombinant virus was purified by three consecutive plaque picking, and a stock virus was prepared by infecting BHK21 cells.

\section{Shake flask virus studies}

For virus infection studies in shake flasks, suspension adapted Vero cells were harvested and seeded at the indicated cell density in fresh medium. Vero cells were infected with rVSV at the indicated MOI and the temperature was shifted to either $34{ }^{\circ} \mathrm{C}$ (rVSV-ZEBOV, rVSV-HIV) or $31{ }^{\circ} \mathrm{C}\left(\mathrm{rVSV}_{\text {Ind }}-m s p-\mathrm{S}_{\mathrm{F}}-\right.$ Gtc $)$. Samples for virus titration were centrifuged for 5 minutes at $1200 \times \mathrm{g}$ to remove cellular debris, aliquoted and stored at $-80 \operatorname{deg} \mathrm{C}$.

\section{Bioreactor cultures}

Bioreactor cultures were performed in a $1 \mathrm{~L}$ bioreactor (Applikon Biotechnology, The Netherlands) equipped with a marine impeller, $\mathrm{pH}$ sensor, temperature sensor, and dissolved oxygen (DO) concentration sensor. MDXK medium was supplemented $4 \mathrm{mM}$ L-glutamine (GE Healthcare, USA) instead of GlutaMAX to enable monitoring of L-glutamine consumption. Vero cell seed cultures were grown in progressively larger polycarbonate shake flasks (TriForest Enterprises, USA), harvested by centrifugation and resuspended in fresh medium before inoculation. The bioreactor was inoculated at a cell density of $2.5 \times 10^{5}$ cells $/ \mathrm{mL}$ in $850 \mathrm{~mL}$ working volume. The culture was agitated at $100 \mathrm{rpm}$ and kept at $37 \mathrm{deg}$. The DO concentration was kept at $50 \%$ air-saturation by continuous surface aeration of $5 \mathrm{~mL} / \mathrm{min}$ air and injection of pure 
oxygen through the sparger when required. The $\mathrm{pH}$ was set to 7.2 and regulated by injection of $\mathrm{CO}_{2}$ into the headspace or addition of $\mathrm{NaHCO}_{3}(90 \mathrm{~g} / \mathrm{L})$ (Sigma, USA). Samples were taken once or twice daily, depending on the progress of the culture, to subsequently determine viable cell density, metabolite concentration and virus titer. Samples for metabolite analysis and virus titration were centrifuged for 5 minutes at $1200 \mathrm{xg}$ to remove cellular debris, aliquoted and stored at $-80 \operatorname{deg} \mathrm{C}$.

For virus production, Vero cells were infected with rVSV at an MOI of 0.01 once the targeted cell density was reached and the temperature was shifted to $34 \operatorname{deg} \mathrm{C}$ or $31 \operatorname{degC}$, respectively, during the virus production phase. The glucose concentration was estimated once daily and if required adjusted to $2 \mathrm{~g} / \mathrm{L}$ by feeding glucose (Sigma) concentrate $(180 \mathrm{~g} / \mathrm{L})$. In addition, L-glutamine was maintained at a minimum concentration of $2 \mathrm{mM}$.

\section{Analytical Methods}

Vero cell concentration and viability were determined via the Vi-CELL XR cell counter (Beckman Coulter, USA). The Median Tissue Culture Infectious Dose $\left(\mathrm{TCID}_{50}\right)$ assay and digital PCR assay used in this work to quantify the infectious titer and the number of viral genomes, respectively, has been described previously (Gelinas et al., 2020; Kiesslich et al., 2020). For $\mathrm{rVSV}_{\text {Ind }}-m s p-\mathrm{S}_{\mathrm{F}}-$ Gtc, the TCID 50 plates were incubated at $31 \operatorname{deg} \mathrm{C}$, due to the temperature sensitivity of this construct.

\section{Metabolite analysis}

During cell culture cultivations, the glucose concentration was estimated using the D-Fructose/D-Glucose Assay Kit (Megazyme, Ireland). More extensive metabolite analysis was performed offline via Bioprofile 400 (Nova Biomedical, USA) from samples that were stored at $-80 \mathrm{deg}$.

\section{Results and Discussion}

\section{Cell growth of Vero cells in suspension cultures}

\section{Screening for commercial media}

Suspension adapted Vero cells grew well in shake flasks in IHM03 medium up to a cell density of around $2 \times 10^{6}$ cells $/ \mathrm{mL}$ and with doubling times of around $48 \mathrm{~h}$ as previously reported (Shen et al., 2019). IHM03 is an in-house medium developed and produced in small batches by the NRC, supporting the growth and virus production of Vero suspension cultures. As reported by Shen et al. and Rourou et al., media composition is critical for successfully generating a suspension adapted Vero cell line and no commercial media was able to support Vero cell adaptation so far (Rourou et al., 2019; Shen et al., 2019). Despite these recently reported adaptation successes with in-house media, establishing a process using commercial media could reduce the risk of lot-to-lot variations and would make the platform more amenable to work under standard conditions when media supply is assured.

Therefore, efforts have been dedicated to assessing different commercial media. After 20 passages of gradual adaptation in shake flasks, a Vero cell line was obtained that was able to grow in MDXK medium (Xell $\mathrm{AG}$ ) supplemented with $4 \mathrm{mM}$ Glutamax and which exhibited cell doubling times of around 48-72 $\mathrm{h}$ (data not shown). Other commercial media that were tested, but did not support growth of Vero cells in suspension culture included VP-SFM, OptiPRO, FreeStyle 293 (Thermo Fisher Scientific, USA), HyClone HyCell TransFx-H (GE Healthcare, USA), HEK GM (Xell AG, Germany) and ProVeroTM -1 serum free medium (SFM) (Lonza, Switzerland).

Despite slightly slower growth rates in MDXK than in IHM03 in shake flasks, the cells were able to grow to similar cell densities in batch shake flasks with less formation of cell aggregates. Compared to other 
mammalian suspension cell lines, like derivatives of HEK293 or CHO with cell doubling times of $24 \mathrm{~h}$, there is still great potential to develop media that can support similar growth rates.

\section{Cell growth in batch bioreactor}

The suspension adapted Vero cells showed similar growth in IHM03 medium in 1L batch bioreactors as previously reported, reaching $1.78 \times 10^{6}$ cells $/ \mathrm{mL}$ after 6 days (Shen et al., 2019). Cell viability was above $99 \%$ during the whole run. The doubling time was around 51 hours for the entire batch process duration between cell seeding and peak in maximum cell density, and around 40 hours for the exponential cell growth phase between cell seeding up until 96 hours (Figure $1 \mathrm{~A}$ ). The substrates glucose and glutamine were almost depleted at the end of the culture. Ammonia was produced throughout and stayed below concentrations of $4 \mathrm{mM}$. Lactate production reached a concentration of $24.5 \mathrm{mM}$ after 96 hours, but declined thereafter which can be explained by an uptake of lactate by the cells as previously reported (Quesney et al., 2003).

Cell growths in MDXK medium was slightly slower and only reached $1.45 \times 10^{6}$ cells $/ \mathrm{mL}$ after 7 days (Figure 1B). However, in contrast to the shake flask experiments, Vero cells in MDXK medium showed a higher degree of aggregate formation in the bioreactor compared to cells in IHM03. This could have led to an underestimation of the cell count, which is also indicated by a higher glucose consumption rate in MDXK. Cell viability again was above $99 \%$ throughout the process. As opposed to the previous run, glucose and glutamine were depleted earlier and required feeding, adjusting glucose to $2 \mathrm{~g} / \mathrm{L}$ and glutamine to $2 \mathrm{mM}$ once daily starting on day 2 for glutamine and day 6 for glucose. Ammonia production was similar, never exceeding concentrations of $4 \mathrm{mM}$. Lactate production, however, was significantly higher and surpassed 50 $\mathrm{mM}$ at the end of the culture. Lactate was not consumed by the cells in MDXK medium indicating significant differences in the cell metabolism in the two media.

\section{rVSV-ZEBOV production in shake flask}

rVSV-ZEBOV production experiments were initially carried out at a smaller scale in shake flasks to test multiple conditions simultaneously. In particular, the effects of varying multiplicities of infection (MOI), which is the ratio of infectious particles to the number of cells at the time of infection (TOI), as well as infections at different cell densities and in different growth media were screened.

During the late stages of the cultivation when cell densities exceeded $1 \times 10^{6}$ cells $/ \mathrm{mL}$, cells started to adhere to the surface of the shake flask and cell aggregates were formed, which made it quite difficult to accurately determine the cell count. Therefore, initial experiments to investigate the infection kinetics of rVSV-ZEBOV in suspension adapted Vero cells, were carried out by seeding a single cell culture in fresh medium at a cell density of $1 \times 10^{6}$ cells $/ \mathrm{mL}$ and cells were infected immediately thereafter.

Previous studies of rVSV-ZEBOV in adherent Vero cells and suspension cultures of HEK293 cells have shown that infection at a reduced temperature of $34 \operatorname{deg} C$ led to higher infectious titers compared to $37 \operatorname{deg} C$ (Kiesslich et al., 2020)(Gelinas et al., 2019). Based on these studies, the temperature was lowered to 34 degC after infection in all experiments of this work involving rVSV-ZEBOV.

\section{Multiplicity of infection}

Vero cells were infected with rVSV-ZEBOV at different MOIs and samples were taken every 12 hours to determine infection kinetics (Figure 2 ). For the selected range of MOI, peak production of rVSVZEBOV occurred between 24 and 36 hours post infection (hpi) and the titers were in the same range with $1.10 \times 10^{7} \mathrm{TCID}_{50} / \mathrm{mL}, 1.05 \times 10^{7} \mathrm{TCID}_{50} / \mathrm{mL}$ and $1.58 \times 10^{7} \mathrm{TCID}_{50} / \mathrm{mL}$ at an MOI of $0.001,0.01$ and 0.1 , respectively. In all cases, the infectivity declined after the maximum titer had been reached. Similar kinetics have been observed for adherent growing Vero cells, however, the titers were more than eight times higher in adherent cell experiments, for example $8.79 \times 10^{7} \mathrm{TCID}_{50} / \mathrm{mL}$ at an MOI of 0.01 at $36 \mathrm{hpi}$ (Kiesslich et al., 2020). Further, the cell density at the time of infection was more than three times higher for the suspension cultures than for the adherent cell cultures in the reported study, indicating even lower virus production per 
cell. It is to mention that adherent Vero cells were cultivated in commercially available media, optimized for cell growth and virus production.

rVSV infections of adherent Vero cells typically lead to a very distinct cytopathic effect, where cells become round shaped and eventually lift off from the surface. Of note, since suspension cells are already round shaped and not attached to a surface, the cytopathic effect induced by rVSV infections was less noticeable in the early stages of infection and only became more apparent when the cell diameter increased due to viral replication and when cells started to die from lysis caused by viral release.

Nevertheless, based on these experiments and in accordance with our previous work, it was decided to continue all subsequent rVSV experiments at an MOI of 0.01 .

\section{Cell density}

rVSV-ZEBOV replication in Vero cells seeded at different cell densities was investigated to evaluate the effect of varying cell densities and to assess if the production yield was affected by the cell growth phase or metabolite concentrations at the time of infection. Figure 3shows rVSV-ZEBOV infection at $1 \times 10^{6}$ cells $/ \mathrm{mL}, 2 \times 10^{6}$ cells $/ \mathrm{mL}$ and $4 \times 10^{6}$ cells $/ \mathrm{mL}$. The viral infection kinetics were slower compared to the previous experiments and infectious titers peaked at 48 hpi for all cases, indicating considerable variation between experiments. Additionally, maximum infectious titers were around three times higher for the run at $1 \times 10^{6}$ cells $/ \mathrm{mL}$, reaching $3.28 \times 10^{7} \mathrm{TCID}_{50} / \mathrm{mL}$. Throughout the time course of the experiment, titers were even higher at $2 \times 10^{6}$ cells $/ \mathrm{mL}$, but the maximum infectious titer was not significantly elevated at 48 hpi. For the run with a seeding cell density of $4 \times 10^{6}$ cells $/ \mathrm{mL}$, infectious titers of rVSV-ZEBOV were significantly higher, reaching $1.32 \times 10^{8} \mathrm{TCID}_{50} / \mathrm{mL}$, exceeding infectious titers obtained from adherent Vero studies in 6-well plates (Kiesslich et al., 2020). In comparison, for rVSV-GFP produced in suspension cell cultures of Vero cells at different cell densities in a similar experiment, 3.8 times higher virus titers were obtained at $2.5 \times 10^{6}$ cells $/ \mathrm{mL}$ compared to $0.87 \times 10^{6}$ cells $/ \mathrm{mL}$ (Shen et al., 2019). But a further increase in cell density from $2.5 \times 10^{6}$ cells $/ \mathrm{mL}$ to $5 \times 10^{6}$ cells $/ \mathrm{mL}$ did not result in higher infectious titers.

These results indicate that suspension cultures of Vero cells could be a viable alternative if high cell density processes of suspension cultures can be achieved at larger scale, but further research is necessary to investigate effects of high cell density in more detail. One advantage though is that suspension cultures are not limited by the surface area, as is the case for adherent cell cultures using microcarriers, roller bottles or fixed-bed bioreactors, which is the prevalent mode of virus production in Vero cells. Nevertheless, these results need to be carefully evaluated since it might be challenging to seed bioreactors in fresh medium at high cell density

\section{rVSV-ZEBOV, rVSV-HIV, and $\mathrm{rVSV}_{\text {Ind }}-m s p-\mathrm{S}_{\mathrm{F}}-$ Gtc shake flask production in different media}

Next, the kinetics of three variants, namely rVSV-ZEBOV, rVSV-HIV, and $\mathrm{rVSV}_{\text {Ind }}-m s p$-S $\mathrm{S}_{\mathrm{F}}$-Gtcwere compared and the effect of different media on rVSV production were studied. Based on temperature study results of rVSV-ZEBOV infections in Vero cells, rVSV-HIV infections were carried out at $34 \operatorname{degC}$ in a recent study and this condition was adopted for this work as well (Mangion et al., 2020). The $\mathrm{rVSV}_{\text {Ind }}-m s p$ - $\mathrm{S}_{\mathrm{F}}$-Gtcconstruct, however, is temperature sensitive and therefore all infections were carried out at $31 \operatorname{degC}$.

The IHM03 and MDXK adapted cell lines were infected with rVSV to compare the virus production capacity of both media. Despite higher titers obtained at higher cell densities (Figure 3 ), these experiments were carried out at a seeding cell density of $1 \times 10^{6} \mathrm{cells} / \mathrm{mL}$ to avoid cell aggregation. Figure 4 shows rVSVZEBOV (A), rVSV-HIV (B) and $\mathrm{rVSV}_{\text {Ind }}-m s p-\mathrm{S}_{\mathrm{F}}-$ Gtc $(\mathrm{C})$ replication in the MDXK adapted cell line at an MOI of 0.01 in comparison to the corresponding experiment conducted in IHM03.

rVSV-ZEBOV replication in MDXK medium reached slightly higher titers than in IHM03 medium (Figure $4 \mathrm{~A}$ ). Where the infectious titer reached a maximum at $24 \mathrm{hpi}$ in IHM03, the titer in MDXK was with $2.63 \times 10^{7} \mathrm{TCID}_{50} / \mathrm{mL}$ around 2.5 times higher. Otherwise, almost identical infection kinetics were observed. 
rVSV-HIV replicated better in IHM03 with a higher maximum titer of $9.59 \times 10^{6} \mathrm{TCID}_{50} / \mathrm{mL}$ reached in a shorter period of time (24 hpi) compared to $2.08 \times 10^{6} \mathrm{TCID}_{50} / \mathrm{mL}$ in MDXK after 36 hpi (Figure $4 \mathrm{~B}$ ). Titers of rVSV-HIV were lower in both media than rVSV-ZEBOV and the infectivity declined faster than for rVSV-ZEBOV. Besides, rVSV-HIV produced in adherent Vero cells reached up to $3.91 \times 10^{7} \mathrm{TCID}_{50} / \mathrm{mL}$ at MOI of 0.01. However, the peak was reached significantly later at 96 hpi (Mangion et al., 2020).

In contrast to these two strains, $\mathrm{rVSV}_{\text {Ind }}-m s p-\mathrm{S}_{\mathrm{F}}-G t c$ reached significantly higher titers (Figure $4 \mathrm{C}$ ). In MDXK, $5.19 \times 10^{8} \mathrm{TCID}_{50} / \mathrm{mL}$ were reached at $36 \mathrm{hpi}$. In IHM03, almost two-fold higher titers with $1.17 \times 10^{9} \mathrm{TCID}_{50} / \mathrm{mL}$ were reached. However, it took additional 24 hours to reach this titer, which aligns with the beginning of the replication phase being delayed. In addition to higher infectious titers compared to rVSV-ZEBOV and rVSV-HIV, the infectivity of viral particles did not decline significantly over the following sample time points.

Higher infectious titers of $\mathrm{rVSV}_{\text {Ind }}-m s p-\mathrm{S}_{\mathrm{F}}-$ Gtc in Vero cells could be linked to the use of different transmembrane domains. Whereas rVSV-ZEBOV and rVSV-HIV use Ebola GP or SIV transmembrane domains (Mangion et al., 2020), $\mathrm{rVSV}_{\text {Ind }}-m s p-\mathrm{S}_{\mathrm{F}}-$ Gtc is expressing the native VSV-G protein transmembrane domain gene. It has been shown that the stem region of the VSV-G glycoprotein was important for efficient virus assembly, and viruses with shortened sequences were replicated up 20-fold less (Robison and Whitt, 2000). More research investigating the use of different transmembrane domains with the same extracellular domain could reveal interesting aspects on virus replication rates and identify new targets to improve the rVSV platform. Nevertheless, it might be more appropriate to compare replication of $\mathrm{rVSV}_{\text {Ind }}-m s p-\mathrm{S}_{\mathrm{F}}-$ Gtc to rVSV-GFP production, which also uses the native VSV-G protein transmembrane domain, and where titers of up to $8.93 \times 10^{9} \mathrm{TCID}_{50} / \mathrm{mL}$ have been obtained in shake flask experiments.

Besides, the lower process temperature of $31 \mathrm{degC}$ is likely affecting the infectivity. For example, the infectivity of this strain was not declining over the following $36 \mathrm{~h}$ after the peak titer had been reached thus potentially stabilizing infectivity. Though for rVSV-ZEBOV, an optimal production temperature of $34 \operatorname{deg} \mathrm{C}$ was determined in adherent Vero cells (Kiesslich et al., 2020), $\mathrm{rVSV}_{\text {Ind }}-m s p-\mathrm{S}_{\mathrm{F}}-$ Gtc is based on $\mathrm{VSV}_{\text {Ind }}(\mathrm{GML})$ which was adapted to replicate well at the lower temperature of $31 \operatorname{deg} \mathrm{C}$ (Figure $4 \mathrm{C}$ ).

\section{Bioreactor processes of suspension adapted Vero cells}

\section{Bioreactor production of rVSV-ZEBOV}

Two bioreactors of Vero cells were infected at a cell density of $1.37 \times 10^{6}$ cells $/ \mathrm{mL}$ and $1.02 \times 10^{6}$ cells $/ \mathrm{mL}$ after cells grew for 4 days in IHM03 and MDXK medium, respectively (Figure $\mathbf{5}$ ). The cell growth phase corresponded well to the data shown in Figure 1. Despite a lower cell density at the TOI, maximum infectious titers were with $3.87 \times 10^{7} \mathrm{TCID}_{50} / \mathrm{mL}$ more than one log higher than in IHM03, were only $3.55 \times 10^{6} \mathrm{TCID}_{50} / \mathrm{mL}$ were obtained. In addition, replication was faster in MDXK, were peak production occurred at $24 \mathrm{hpi}$ compared to $36 \mathrm{hpi}$, respectively. The MDXK bioreactor also exhibited an almost 15times higher cell specific productivity with $37.9 \mathrm{TCID}_{50} /$ cell compared to $2.6 \mathrm{TCID}_{50} /$ cell. Moreover, the ratio of total viral particles to infectious particles was lower in MDXK (282 VG/TCID 50 ) than in IHM03 $\left(817 \mathrm{VG} / \mathrm{TCID}_{50}\right)$, further indicating a better quality of the final product if harvested at the time of peak infectious titer.

Compared to the shake flask experiments, rVSV-ZEBOV replication in MDXK medium reached a slightly higher maximum infectious titer, indicating a successful scale-up. For IHM03, titers were three times lower than in shake flask and the peak was reached 12 hours later.

Further, in comparison to adherent Vero bioreactor productions of rVSV-ZEBOV, the production using suspension adapted Vero cells in MDXK appears superior. The infectious titer and the cell specific productivities were slightly higher compared to the production in a microcarrier bioreactor $\left(1.42 \times 10^{7} \mathrm{TCID}_{50} / \mathrm{mL}\right.$, $7.6 \mathrm{TCID}_{50} /$ cell $)$ and a fixed-bed bioreactor $\left(2.59 \times 10^{7} \mathrm{TCID}_{50} / \mathrm{mL}, 11.2 \mathrm{TCID}_{50} /\right.$ cell $)$. The ratio of total viral particles to infectious particles was four times lower than in the microcarrier but nine times higher 
compared to the fixed-bed process (Kiesslich et al., 2020). Overall, the suspension Vero system is a viable alternative to the current Vero manufacturing system carried out in roller bottles for this Ebola virus disease vaccine (Monath et al., 2019).

When set side by side to a suspension bioreactor production of rVSV-ZEBOV in HEK293-SF, where a maximum of $1.19 \times 10^{8} \mathrm{TCID}_{50} / \mathrm{mL}$ was reached, production in Vero cells in MDXK was 3 times lower. However, it can be expected that future media development, bioprocess and cell line engineering of suspension Vero can lead to significantly higher titers comparable to HEK293-SF (Gelinas et al., 2019).

\section{Bioreactor production of rVSV-HIV}

Two bioreactors were prepared as before, and Vero cell growth phase in IHM03 and MDXK medium was consistent with the data from Figure 1 and Figure $\mathbf{5}$. The two cultures were infected with rVSV-HIV after 4 days (Figure 6 ). In contrast to the previous experiment, virus production was favoured in IHM03 over MDXK. In IHM03, rVSV-HIV reached a maximum titer of $2.12 \times 10^{7} \mathrm{TCID}_{50} / \mathrm{mL}$, which was 25 -times higher than in MDXK. However, production kinetics of viral genomes were almost identical. This is supported by a lower ratio of $143 \mathrm{VG} / \mathrm{TCID}_{50}$ (IHM03) compared to $7041 \mathrm{VG} / \mathrm{TCID}_{50}$ (MDXK). Additionally, the fact that the cell specific productivity in MDXK was 0.9 TCID $_{50} /$ cell implies that the rVSV-HIV/MDXK system failed to scale-up and is not an adequate production system.

Besides, the shake flask experiment (Figure 4 B) already indicated the superiority of IHM03 for rVSV-HIV replication. Moreover, bioreactor production of rVSV-HIV in IHM03 exceeded titers from the smaller scale, whereas bioreactor titers in MDXK subsided the small scale.

\section{Bioreactor production of $\mathrm{rVSV}_{\mathrm{Ind}}-m s p-\mathrm{S}_{\mathrm{F}^{-}}$Gtc}

Finally, $\mathrm{rVSV}_{\text {Ind }}-m s p-\mathrm{S}_{\mathrm{F}}-$ Gtcproduction in bioreactors of Vero suspension cell cultures was studied (Figure 7 ). Again, the cell growth phase was comparable to the previous runs, and cells were infected after 4 days. Infectious titers of $\mathrm{rVSV}_{\text {Ind }}-m s p-\mathrm{S}_{\mathrm{F}}-$ Gtcpeaked in both media at $48 \mathrm{hpi}$. The beginning of the replication phase was delayed in IHM03, as already seen in the shake flask experiments. Nevertheless, titers were similar with $2.38 \times 10^{9} \mathrm{TCID}_{50} / \mathrm{mL}$ in IHM03 and $3.59 \times 10^{9} \mathrm{TCID}_{50} / \mathrm{mL}$ in MDXK. Thus, results from the shake flask experiment were exceeded by two-fold and seven-fold, respectively. On the one hand, the quality in terms of total viral particles to infectious particles was with $3.0 \mathrm{VG} / \mathrm{TCID}_{50}$ better in IHM03 than in MDXK, where this value was $6.0 \mathrm{VG} / \mathrm{TCID}_{50}$. On the other hand, the cell specific productivity was doubled in MDXK compared to IHM03, with $3670 \mathrm{TCID}_{50} /$ cell and $1803 \mathrm{TCID}_{50} /$ cell, respectively.

In comparison, rVSV-ZEBOV and rVSV-HIV productions in the bioreactor peaked earlier. However, the number of viral genomes continued to increase in those experiments even when the infectious titer declined. Therefore, the rate of viral degradation is higher than the viral production rate after the corresponding peak was reached in the case of these two strains, potentially due to the higher process temperature of $34 \operatorname{deg} \mathrm{C}$ versus $31 \operatorname{deg} \mathrm{C}$ and its impact on viral stability.

Overall, the scale-up of $\mathrm{rVSV}_{\text {Ind }}-m s p-\mathrm{S}_{\mathrm{F}}-$ Gtcproduction to the bioreactor was successful, exceeding small scale results. In addition, this strain appears to replicate to much higher titers, with a superior cell specific productivity and an improved ratio of VG/TCID 50 as compared to rVSV-ZEBOV and rVSV-HIV.

\section{Conclusion}

In this work, we have demonstrated the feasibility and applicability of suspension adapted Vero cell cultures for the production of highly relevant rVSV-based vaccines and vaccine candidates. For three rVSV strains, namely rVSV-ZEBOV, rVSV-HIV and $\mathrm{rVSV}_{\text {Ind }}-m s p-\mathrm{S}_{\mathrm{F}}-G t c$, production was successfully scaled-up to the bioreactor scale. Table 1 shows a summary of the six bioreactor runs, comparing results for the three strains 
in two different culture media. Further, proof-of-concept is provided that rVSV-ZEBOV and $\mathrm{rVSV}_{\text {Ind }}-m s p$ $-\mathrm{S}_{\mathrm{F}}-$ Gtc can be produced in commercially available media in suspension adapted Vero cells.

Process parameters developed in suspension Vero and previously in adherent Vero cells for rVSV-ZEBOV (Kiesslich et al., 2020), have been shown to be applicable to other strains. This is an important observation as rVSV-ZEBOV can thus serve as a model virus for other rVSV strains. More, this can be of significant value for the production of future rVSV-based vaccine candidates against emerging infectious diseases.

Moreover, the production of rVSV-ZEBOV was shown to be superior to previously developed adherent processes in microcarrier and fixed-bed bioreactors (Kiesslich et al., 2020). Due to the better scalability, the suspension Vero system can serve as a viable alternative to the current Ebola virus disease vaccine manufacturing using roller bottles.

Production of rVSV-ZEBOV was leading to higher infectious titers in suspension cultures of HEK293-SF (Gelinas et al., 2019). However, this system used commercially available media and bioprocesses developed with years of experience. The commercially available MDXK medium has only been on the market for a short period of time. Hence, there is great potential for optimization of Vero suspension media and bioprocesses specifically for virus production.

In the context of the current COVID-19 pandemic, this work shows relevant advancement in the field of bioprocess development for urgently needed vector-based vaccine candidates. Given that $\mathrm{rVSV}_{\mathrm{Ind}}-m s p-\mathrm{S}_{\mathrm{F}^{-}}$ Gtc grows to titers that are around 100-fold higher than titers of rVSV-ZEBOV in the same system, and given that rVSV-ZEBOV produced in conventional roller bottle processes has been approved as a vaccine candidate by regulatory agencies, the herein presented bioprocess using suspension adapted Vero cells can serve as a highly efficient system for accelerated and scalable manufacturing of a COVID-19 vaccine candidate. Further, the quality of the produced viruses in terms of the ratio total particles to infectious particles is far superior, potentially leading to facilitated downstream processes and ultimately very economical manufacturing.

In the future, fed-batch and perfusion processes should be developed for high cell density bioreactors. As indicated in shake flask experiments and already demonstrated for VSV-GFP (Shen et al., 2019), these can be approaches to further push the boundaries and to increase virus productivities of the suspension Vero system.

\section{Declaration of Competing Interest}

The authors declare that they have no known competing financial interests or personal relationships that could have appeared to influence the work reported in this paper.

\section{Acknowledgement}

Dr. Kamen received funding from the Canadian Institutes of Health Research Grant OVV 152411. Sascha Kiesslich was funded by a doctoral scholarship from the Fonds de Recherche du Quebec - Sante (FRQS). Dr. Kang received funding from CIHR Grant RES002426 and Sumagen Canada.

\section{Author contributions}

Sascha Kiesslich: Conceptualization, Investigation, Formal analysis, Writing - Original Draft, Writing - Review \& Editing.Gyoung Nyoun Kim: Construction and characterization of $\mathrm{rVSV}_{\text {Ind }}-m s p-\mathrm{S}_{\mathrm{F}}-$ Gtc .Chun Fang Shen: Investigation, Writing - Review \& Editing.C. Yong Kang: Conceptualization, Writing - Review \& Editing, Supervision, Funding acquisition. Amine A. Kamen:Conceptualization, Writing Review \& Editing, Supervision, Funding acquisition. 


\section{Literature}

Folegatti PM, Ewer KJ, Aley PK, Angus B, Becker S, Belij-rammerstorfer S, Bellamy D, Bibi S, Bittaye M, Clutterbuck EA, Dold C, Faust SN, Finn A, Flaxman AL, Hallis B, Heath P, Jenkin D, Lazarus R, Makinson R, Minassian AM, Pollock KM, Ramasamy M, Robinson H, Snape M, Tarrant R, Voysey M, Green C, Douglas AD, Hill AVS, Lambe T, Gilbert SC, Pollard AJ. Safety and immunogenicity of the ChAdOx1 nCoV19 vaccine against SARS-CoV-2: a preliminary report of a phase $1 / 2$, single-blind, randomised controlled trial:467-478.

Gelinas J-F, Azizi H, Kiesslich S, Lanthier S, Perdersen J, Chahal PS, Ansorge S, Kobinger G, Gilbert R, Kamen AA. 2019. Production of rVSV-ZEBOV in serum-free suspension culture of HEK 293SF cells. Vaccine 37 :6624-6632. https://linkinghub.elsevier.com/retrieve/pii/S0264410X19312538.

Gelinas J, Kiesslich S, Gilbert R, Kamen AA. 2020. Titration methods for rVSV-based vaccine manufacturing. MethodsX 7 .

Henao-Restrepo AM, Camacho A, Longini IM, Watson CH, Edmunds WJ, Egger M, Carroll MW, Dean NE, Diatta I, Doumbia M, Draguez B, Duraffour S, Enwere G, Grais R, Gunther S, Gsell PS, Hossmann S, Watle SV, Konde MK, Keita S, Kone S, Kuisma E, Levine MM, Mandal S, Mauget T, Norheim G, Riveros X, Soumah A, Trelle S, Vicari AS, Rottingen J-A, Kieny M-P. 2017. Efficacy and effectiveness of an rVSV-vectored vaccine in preventing Ebola virus disease: final results from the Guinea ring vaccination, open-label, cluster-randomised trial (Ebola Ca Suffit!).Lancet 389 :505-518. http://www.sciencedirect.com/science/article/pii/S0140673616326216.

Kiesslich S, Kamen AA. 2020. Vero cell upstream bioprocess development for the production of viral vectors and vaccines. Biotechnol. Adv. 44 . https://doi.org/10.1016/j.biotechadv.2020.107608.

Kiesslich S, Losa JPV, Gelinas J, Kamen AA. 2020. Serum-free production of rVSV-ZEBOV in Vero cells: Microcarrier bioreactor versus scale-X ${ }^{\mathrm{TM}}$ hydro fixed-bed. J. Biotechnol.310:32-39. https://doi.org/10.1016/j.jbiotec.2020.01.015.

Kim GN, Wu K, Hong JP, Awamleh Z, Kang CY. 2015. Creation of Matrix Protein Gene Variants of Two Serotypes of Vesicular Stomatitis Virus as Prime-Boost Vaccine Vectors. J. Virol. 89 :6338-6351.

Lichty BD, Power AT, Stojdl DF, Bell JC. 2004. Vesicular stomatitis virus: Re-inventing the bullet. Trends Mol. Med.10 :210-216.

Litwin J. 1992. The growth of Vero cells as suspended aggregates in serum-free medium. Anim. Cell Technol. Butterworth-Heinemann 414-417 p. http://dx.doi.org/10.1016/B978-0-7506-0421-5.50096-9.

Mangion M, Gelinas JF, Bakhshi Zadeh Gashti A, Azizi H, Kiesslich S, Nassoury N, Chahal PS, Kobinger G, Gilbert R, Garnier A, Gaillet B, Kamen A, Bakhshi A, Gashti Z, Azizi H, Kiesslich S, Nassoury N, Chahal PS, Kobinger G, Gilbert R, Garnier A, Gaillet B, Kamen A. 2020. Evaluation of novel HIV vaccine candidates using recombinant vesicular stomatitis virus vector produced in serum-free Vero cell cultures. Vaccine $\mathbf{3 8}$ :7949-7955. https://doi.org/10.1016/j.vaccine.2020.10.058.

Monath TP, Fast PE, Modjarrad K, Clarke DK, Martin BK, Fusco J, Nichols R, Heppner DG, Simon JK, Dubey S, Troth SP, Wolf J, Singh V, Coller B-AA, Robertson JS, Gray Heppner D, Simon JK, Dubey S, Troth SP, Wolf J, Singh V, Coller B-AA, Robertson JS. 2019. rVSV $\Delta$ G-ZEBOV-GP (also designated V920) Recombinant Vesicular Stomatitis Virus Pseudotyped with Ebola Zaire Glycoprotein: Standardized Template with Key Considerations for a Risk/Benefit Assessment. Vaccine X 1 . https://doi.org/10.1016/j.jvacx.2019.100009.

Munis AM, Bentley EM, Takeuchi Y. 2020. A tool with many applications: vesicular stomatitis virus in research and medicine. Expert Opin. Biol. Ther. 00 :1-15. https://doi.org/10.1080/14712598.2020.1787981. 
Paillet C, Forno G, Kratje R, Etcheverrigaray M. 2009. Suspension-Vero cell cultures as a platform for viral vaccine production. Vaccine $\mathbf{2 7}: 6464-6467$.

Quesney S, Marc A, Gerdil C, Gimenez C, Marvel J, Richard Y, Meignier B. 2003. Kinetics and metabolic specificities of Vero cells in bioreactor cultures with serum-free medium. Cytotechnology42 :1-11.

Robison CS, Whitt MA. 2000. The Membrane-Proximal Stem Region of Vesicular Stomatitis Virus G Protein Confers Efficient Virus Assembly.J. Virol. 74 :2239-2246.

Rourou S, Ben Zakkour M, Kallel H. 2019. Adaptation of Vero cells to suspension growth for rabies virus production in different serum free media. Vaccine 37 :6987-6995. https://doi.org/10.1016/j.vaccine.2019.05.092.

Shen CF, Guilbault C, Li X, Elahi SM, Ansorge S, Kamen AA, Gilbert R. 2019. Development of suspension adapted Vero cell culture process technology for production of viral vaccines. Vaccine 37 :6996-7002. https://doi.org/10.1016/j.vaccine.2019.07.003.

Ura T, Yamashita A, Mizuki N, Okuda K, Shimada M. 2020. New vaccine production platforms used in developing SARS-CoV-2 vaccine candidates. Vaccine . https://doi.org/10.1016/j.vaccine.2020.11.054.

World Health Organization. 2020. DRAFT landscape of COVID-19 candidate vaccines - 19 October. https://www.who.int/publications/m/item/draft-landscape-of-covid-19-candidate-vaccines.

\section{Table}

Table 1: Comparison of bioreactor productions of rVSV-ZEBOV, rVSV-HIV and rVSV Ind-msp -S $\mathrm{S}^{-}-$Gtc

\begin{tabular}{|c|c|c|c|c|c|c|}
\hline & $\begin{array}{l}\text { rVSV- } \\
\text { ZEBOV }\end{array}$ & $\begin{array}{l}\text { rVSV- } \\
\text { ZEBOV }\end{array}$ & rVSV-HIV & rVSV-HIV & $\begin{array}{l}\mathrm{rVSV}_{\text {Ind }^{-}} \\
m s p-\mathrm{S}_{\mathrm{F}^{-}}-G t c\end{array}$ & $\begin{array}{l}\mathrm{rVSV}_{\text {Ind }^{-}} \\
m s p-\mathrm{S}_{\mathrm{F}^{-}}-G t c\end{array}$ \\
\hline Medium & IHM03 & MDXK & IHM03 & MDXK & IHM03 & MDXK \\
\hline $\begin{array}{l}\text { Peak } \\
\text { infectious } \\
\text { titer }\end{array}$ & $36 \mathrm{hpi}$ & 24 hpi & 24 hpi & 36 hpi & 48 hpi & 48 hpi \\
\hline $\begin{array}{l}\text { Infectious } \\
\text { titer } \\
\left(\mathrm{TCID}_{50} / \mathrm{mL}\right)\end{array}$ & $3.55 \times 10^{6}$ & $3.87 \times 10^{7}$ & $2.12 \times 10^{7}$ & $8.45 \times 10^{5}$ & $2.38 \times 10^{9}$ & $3.59 \times 10^{9}$ \\
\hline $\begin{array}{l}\text { Genomic titer } \\
(\mathrm{VG} / \mathrm{mL})\end{array}$ & $2.9 \times 10^{9}$ & $1.09 \times 10^{10}$ & $3.30 \times 10^{9}$ & $5.95 \times 10^{9}$ & $7.15 \times 10^{9}$ & $2.13 \times 10^{10}$ \\
\hline $\begin{array}{l}\text { Ratio } \\
\text { VG/TCID }\end{array}$ & 817 & 282 & 143 & 7041 & 3.0 & 6.0 \\
\hline $\begin{array}{l}\text { Cell specific } \\
\text { titer } \\
\left(\mathrm{TCID}_{50} / \text { cell }\right)\end{array}$ & 2.6 & 37.9 & 14.8 & 0.9 & 1803 & 3670 \\
\hline
\end{tabular}

\section{Figure Legends}

Figure 1. Cell growth of suspension adapted Vero cells in IHM03 (A) and MDXK (B) medium in a $1 \mathrm{~L}$ bioreactor in batch mode. The concentration of the main metabolic substrates (glucose, L-glutamine) and by-products (lactate, ammonia) are given in $\mathrm{mM}$.

Figure 2. rVSV-ZEBOV infection of suspension adapted Vero cells at different MOIs ranging from 0.001 to $0.1 \mathrm{in} 125 \mathrm{~mL}$ shake flask in IHM03 medium at a cell density of $1 \times 10^{6}$ cells $/ \mathrm{mL}$. Infectious viral titers 
expressed as $\mathrm{TCID}_{50} / \mathrm{mL}$ are plotted against the time post-infection. Bars represent the mean of the three independent samples \pm standard deviation.

Figure 3. rVSV-ZEBOV infection of suspension adapted Vero cells at different cell densities ranging from $1 \times 10^{6}$ to $4 \times 10^{6}$ cells $/ \mathrm{mL}$ in $125 \mathrm{~mL}$ shake flask in IHM03 medium. Infectious viral titers expressed as TCID $50 / \mathrm{mL}$ are plotted against the time post-infection. Bars represent the mean of the three independent samples \pm standard deviation.

Figure 4. rVSV-ZEBOV (A), rVSV-HIV (B) and $\mathrm{rVSV}_{\text {Ind }}-m s p-\mathrm{S}_{\mathrm{F}}-G t c$ (C) infections of suspension adapted Vero cells cultivated in either IHM03 or MDXK medium at an MOI of 0.01 , in $125 \mathrm{~mL}$ shake flask at a cell density of $1 \times 10^{6}$ cells $/ \mathrm{mL}$. Infectious viral titers expressed as $\mathrm{TCID}_{50} / \mathrm{mL}$ are plotted against the time post-infection. Bars represent the mean of the three independent samples \pm standard deviation.

Figure 5. Comparison of the production of rVSV-ZEBOV in suspension adapted Vero cells cultivated in either IHM03 or MDXK medium in a $1 \mathrm{~L}$ bioreactor in batch mode. Infectious viral titers expressed as $\mathrm{TCID}_{50} / \mathrm{mL}$ and the number of viral genomes in $\mathrm{VG} / \mathrm{mL}$ are plotted against the time post-infection.

Figure 6. Comparison of the production of rVSV-HIV in suspension adapted Vero cells cultivated in either IHM03 or MDXK medium in a $1 \mathrm{~L}$ bioreactor in batch mode. Infectious viral titers expressed as TCID $50 / \mathrm{mL}$ and the number of viral genomes in $\mathrm{VG} / \mathrm{mL}$ are plotted against the time post-infection.

Figure 7. Comparison of the production of $\mathrm{rVSV}_{\text {Ind }}-m s p-\mathrm{S}_{\mathrm{F}}-G t c$ in suspension adapted Vero cells cultivated in either IHM03 or MDXK medium in a $1 \mathrm{~L}$ bioreactor in batch mode. Infectious viral titers expressed as $\mathrm{TCID}_{50} / \mathrm{mL}$ and the number of viral genomes in $\mathrm{VG} / \mathrm{mL}$ are plotted against the time post-infection. 

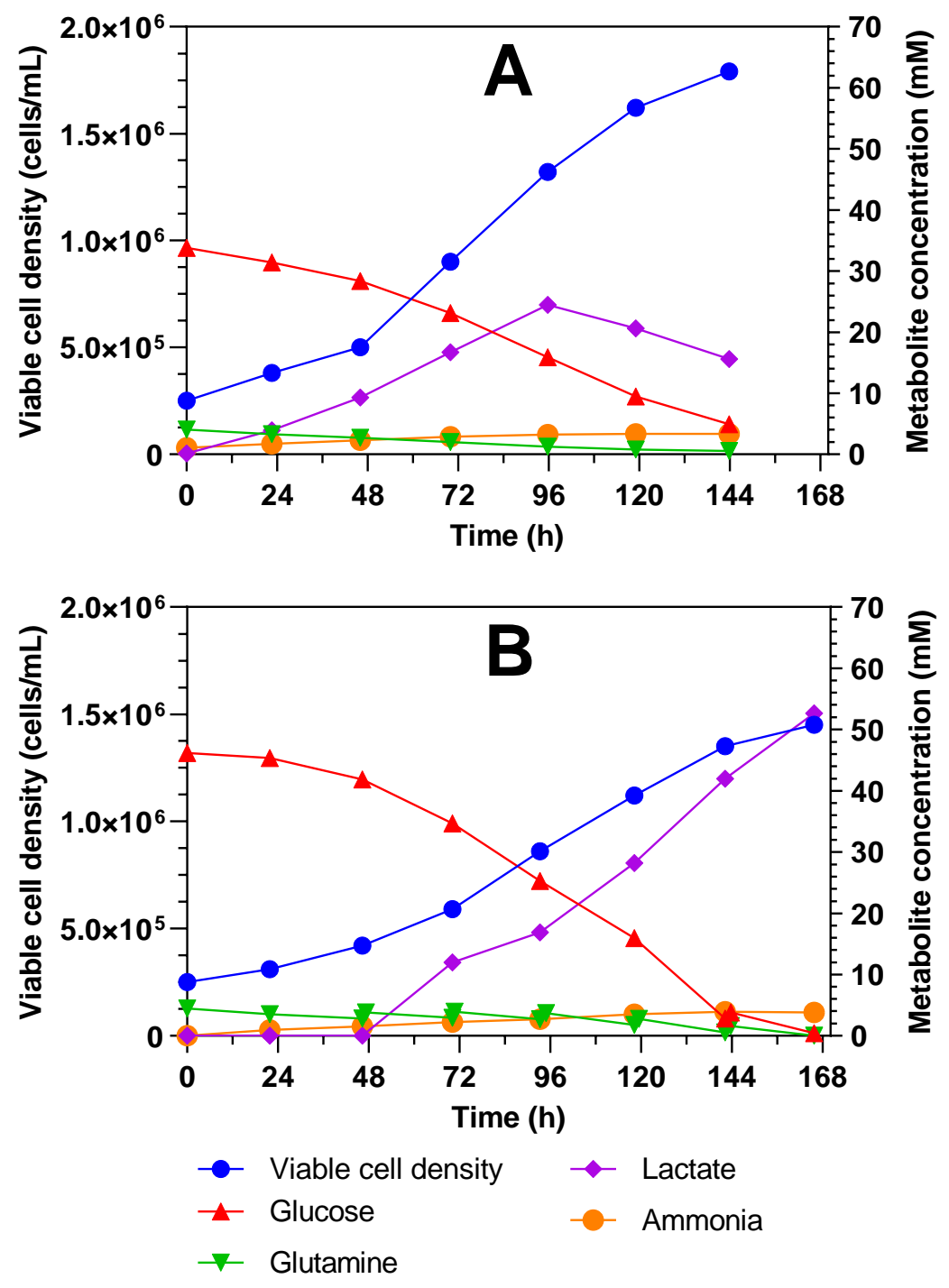


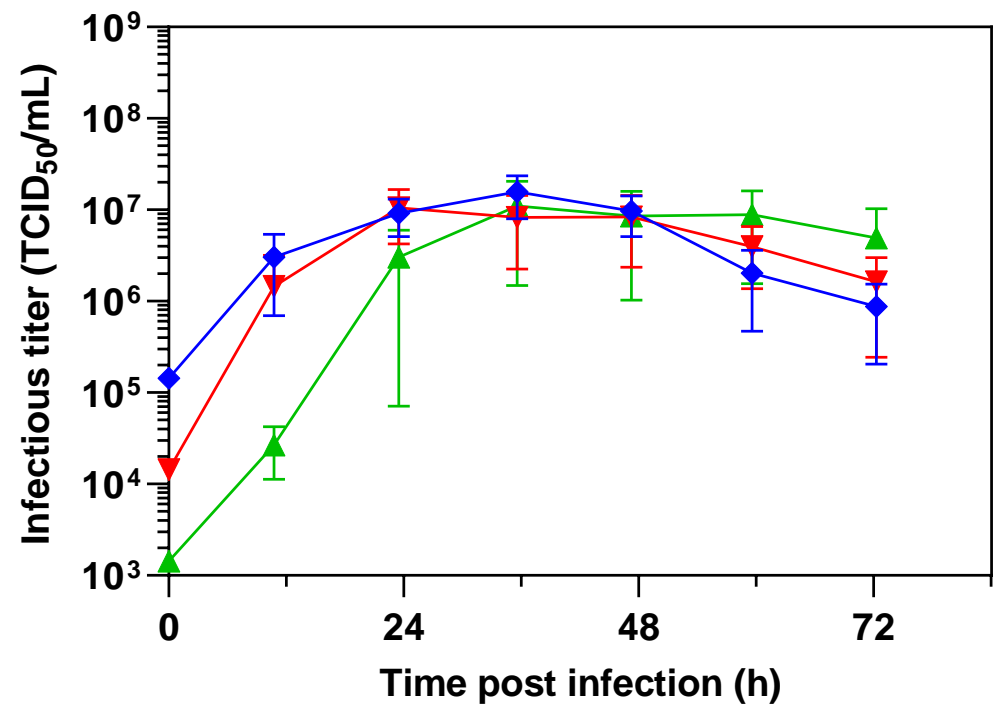

$\neg \mathrm{MOI}=0.001 \rightarrow \mathrm{MOI}=0.01 \rightarrow \mathrm{MOI}=0.1$

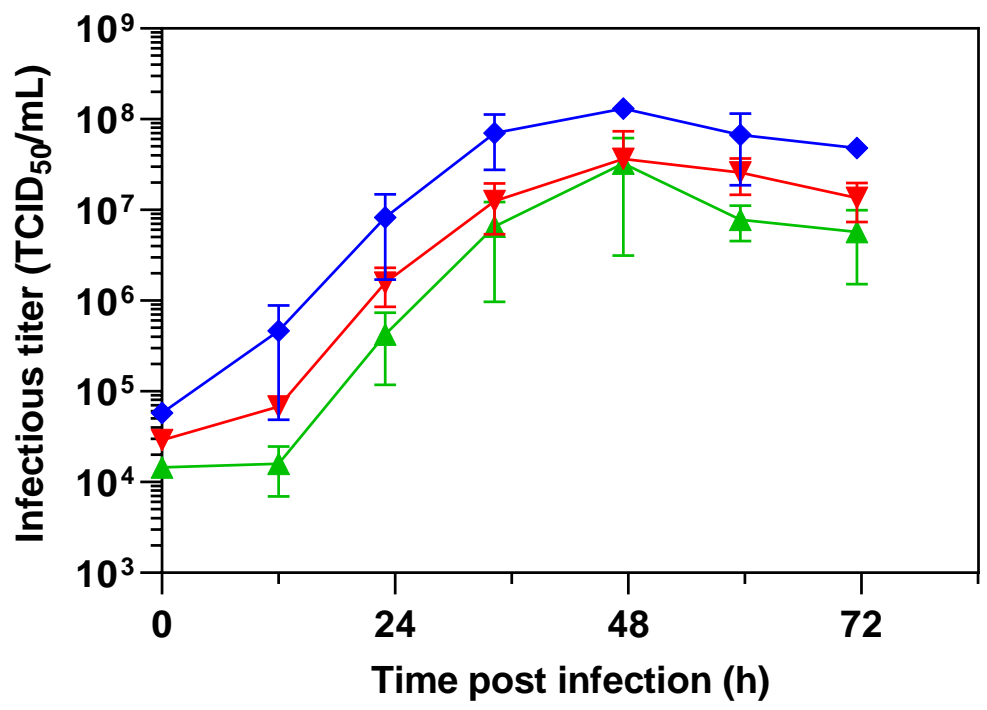

$\neg 1 \times 10^{6} \mathrm{cells} / \mathrm{mL} \rightarrow 2 \times 10^{6} \mathrm{cells} / \mathrm{mL} \multimap 4 \times 10^{6} \mathrm{cells} / \mathrm{mL}$ 

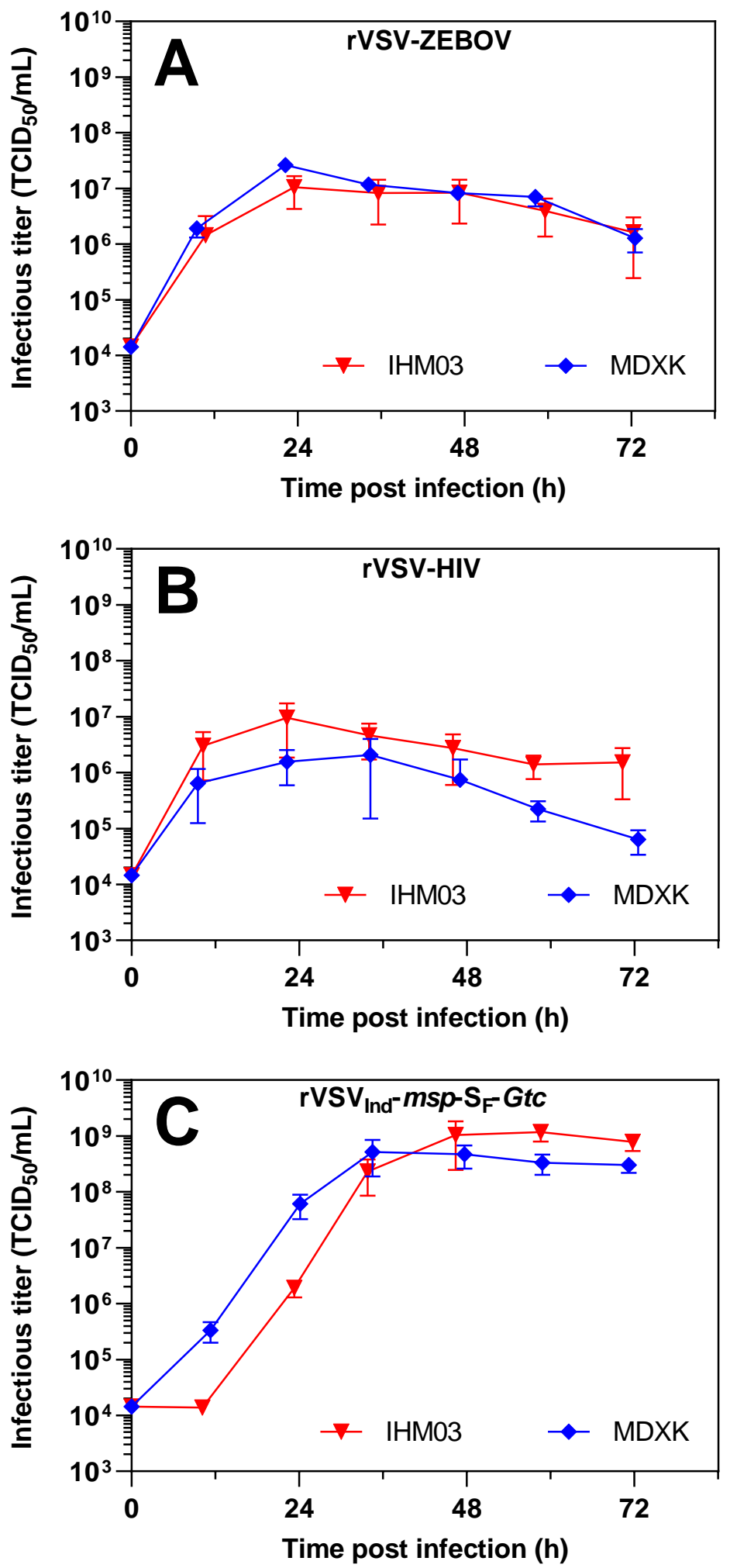


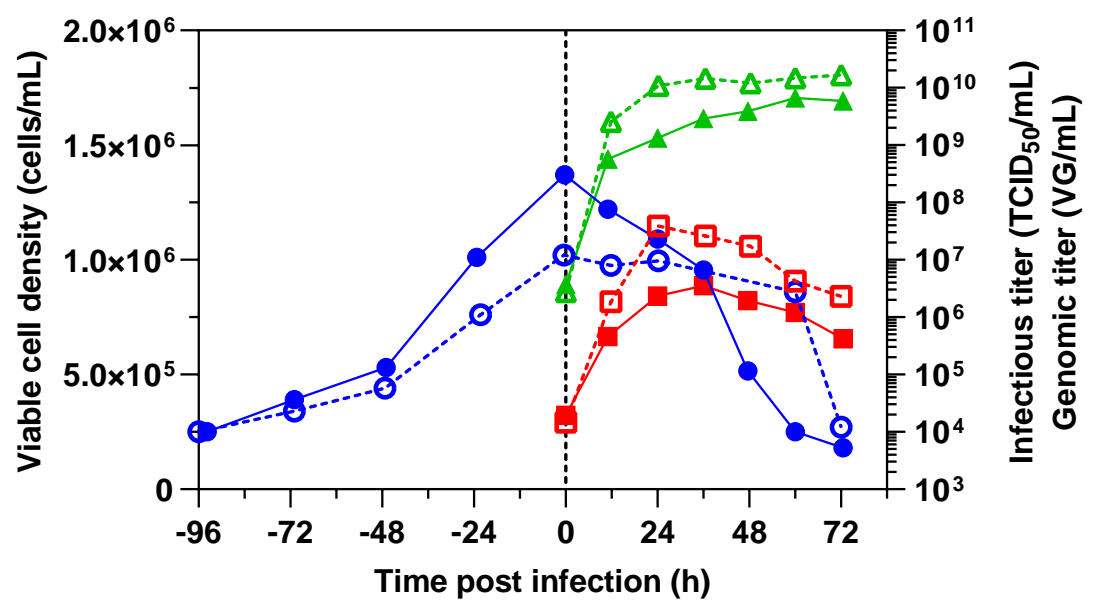
- $\quad$ Viable cell density (IHM03)
- - Viable cell density (MDXK)
- Infectious titer (IHM03)
- $\square$ - Infectious titer (MDXK)
$\neg \quad$ Viral genomes (IHM03)
- $\triangle$-- Viral genomes (MDXK)

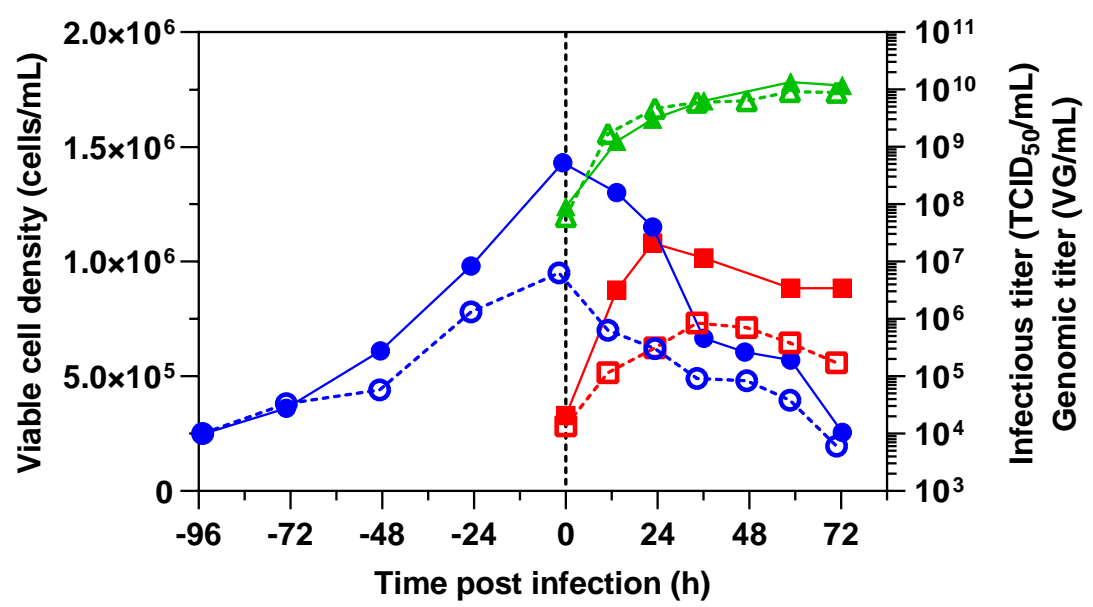
- - Viable cell density (IHM03)
- - Viable cell density (MDXK)
- Infectious titer (IHM03)
- ㅁ. Infectious titer (MDXK)
$\leftarrow$ Viral genomes (IHM03)
- $\Delta$ - Viral genomes (MDXK) 


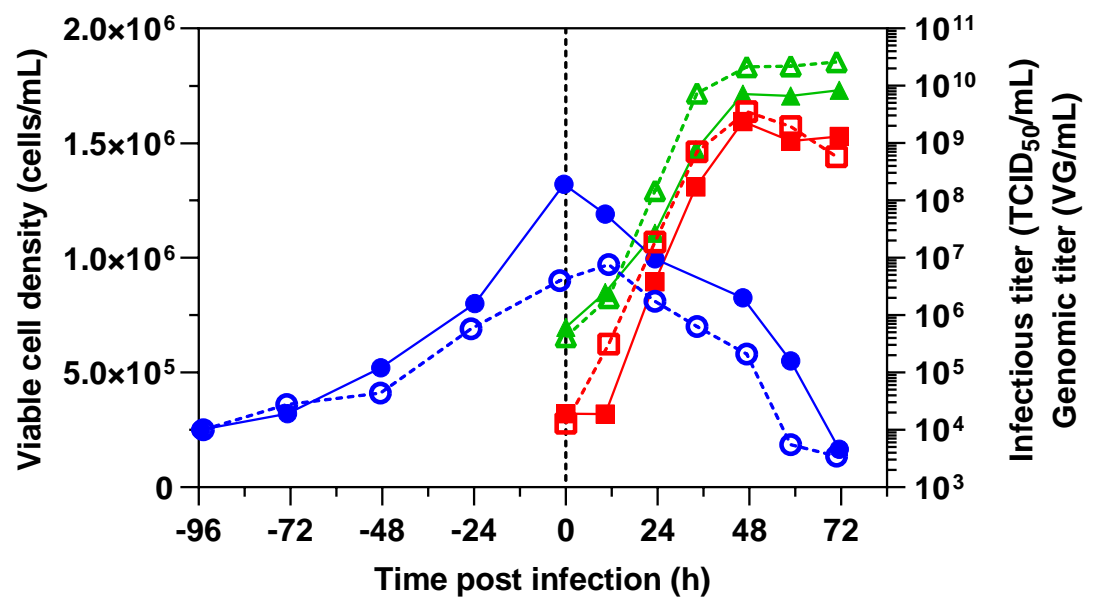

- Viable cell density (IHM03)

- - Viable cell density (MDXK)

-n Infectious titer (IHM03)

- $\square$ - Infectious titer (MDXK)

$\_$Viral genomes (IHM03)

- $\triangle$-- Viral genomes (MDXK) 